\title{
Systems Biology Approach to Study the High Altitude Adaptation in Tibetans
}

\author{
Bi De $^{1}$, Xiao Huajun ${ }^{* 1}$, Zhou Cuihong ${ }^{2}$, Zhou Jun ${ }^{2}$, Deng Xiaoyan ${ }^{2}$ and Liu Xiaopeng ${ }^{3}$ \\ ${ }^{I}$ Department of Human Machine and Environment Engineering; Beihang University \& Institute of Aviation \\ Medicine; Beijing 100191 - China. ${ }^{2}$ School of Biology Science and Medical Engineering; Beihang University; \\ Beijing 100191 - China. ${ }^{3}$ Institute of Aviation Medicine; Beijing 100142 - China
}

\begin{abstract}
The aim of this work was to study an integrative systems biology research strategy to construct a network including the protein-protein interactions (PPIs) and microRNAs (miRNAs) and identify the functional biological processes and pathways for high-altitude adaptation in Tibetans. The pathway enrichment analysis revealed that the genes in the network were mainly involved in signling the pathways and the function of microRNAs was concentrated in the signling pathways, which suggested that miRNAs might contribute to the Tibetans high-altitude adaptation through the participation in signaling pathway. These results contribute to better understanding on the high-altitude adaptation of the Tibetans.
\end{abstract}

Key words: systems biology, Tibetan, high-altitude adaptation, single nucleotide polymorphism, microRNA

\section{INTRODUCTION}

The Tibetans live at the Tibetan Plateau, where the average elevations is above 4,000 meters high and every breath of air contains only nearly $60 \%$ of the oxygen molecules in the same breath at sea level (Beall 2007; Meixue et al. 2010). The Hypoxia (low oxygen) in the Tibet Plateau is the most severe environmental challenges to the local residents. Most people who live at the sea level will show altitude stress, even acute mountain sickness ranging in severity from headache, pulmonary edema, anorexia, nausea, dizziness or disordered sleep to life-threatening pulmonary or cerebral edema because of a lack of oxygen at high altitudes (Basnyat and Murdoch 2003). However, Tibetans who have been living at very high altitudes for thousands of years have heritable adaptations to extreme altitude; they show genetic adaptation to high altitude (Yi et al. 2010).
Compared with the people living at the sea level, the feature in the Tibetans for coping with the hypoxic conditions at high altitude is the decreased Hemoglobin $(\mathrm{Hb})$ levels. Yet the complications related with the sustained high $\mathrm{Hb}$ levels is seen in non-Tibetan lowlanders when they are exposed to high-altitude conditions (Beall 2007; Peng et al. 2011; Simonson et al. 2010; Wu and Kayser 2006). Some genes have shown significant different single nucleotide polymorphisms (SNPs) between the Tibetan and Han populations (Beall et al., 2010; Peng et al., 2011; Simonson et al. 2010; Yi et al. 2010). The Endothelial Per-Arnt-Sim (PAS) domain protein 1 (EPAS1; also termed $H I F 2 \alpha)$ and EGL-nine homolog-1 (EGLNI) play key role in high-altitude adaptation of the Tibetans (Aggarwal et al. 2010; Beall et al. 2010; Bigham et al. 2010; Peng et al. 2011; Xu et al. 2011). Both the EPASI and EGLN1 are involved in the hypoxic pathways as key regulator during the

*Author for correspondence: xiao-hj@263.net 
chronic hypoxia (Peng et al. 2011). The EPASI and EGLN1, which have undergone positive selection, are associated with the Hb levels in the Tibetan populations. The SNPs at EPASI and EGLN1 provides evidence of a genetic contribution to high-altitude adaptation of the Tibetan populations (Aggarwal et al. 2010; Beall et al. 2010; Peng et al. 2011; Simonson et al. 2010; $\mathrm{Xu}$ et al. 2011; Yi et al. 2010).

The EPAS1 is the key regulator during the chronic hypoxia, and it directly regulates the genes such as vascular endothelial growth factor (VEGF), erythropoietin (EPO), and endothelial nitric oxide synthase (eNOS) to cope with the hypoxic conditions (Hu et al. 2003; Patel and Simon 2008; Peng et al. 2011). The EGLN1 is a negative regulator of the EPAS1 and it targets the EPAS1 and Hypoxia inducible factor $1 \alpha$ (HIF1A) for degradation under the normoxic conditions. Under the hypoxic conditions, the degradation effect of the EGLN1 is weakened so that the increase of the EPAS1 protein could initiate the expression of the downstream genes, including $V E G F, E P O$ and eNOS whose product induces red blood cell (RBC) production (Aggarwal et al. 2010; Hu et al. 2003; Patel and Simon 2008; Peng et al. 2011; Simonson et al. 2010). The HIF1A is a key regulator of the tissue response to the hypoxia (Grosfeld et al. 2002; Wang et al. 1995), The EGLN1 negatively regulates the activity of the HIF1A (Aggarwal et al. 2010). The EPAS1 and EGLN1, as well as other proteins, specifically the HIF1A that have interactions with them working together, play a key role in adaptation to high altitude of the Tibetans (Aggarwal et al. 2010; Beall et al. 2010; Bigham et al. 2010).

Although it has been reported that the PPARA has also undergone positive selection and are associated with the $\mathrm{Hb}$ levels in the Tibetan populations and that the haplotype variation at the PPARA contribute to high-altitude adaptation of the Tibetan populations (Simonson et al., 2010), other studies have shown that the tag SNPs at PPARA has no significant allele frequency divergence between the Tibetan and non-Tibetan populations (Peng et al. 2011; Yi et al. 2010). However, some genes tag SNPs have shown significant frequency differences between the Tibetan and non-Tibetan populations (Simonson et al. 2010; Yi et al. 2010). This shows that more indepth studies of these genes function in highaltitude adaptation of the Tibetans are needed. Thus, this work focussed on studying the EPASI and EGLN1 playing key role in high-altitude adaptation of theTibetans. The microRNAs (miRNAs), the $\square 22$ nucleotide (nt) small RNAs involved in the control of gene expression (Bartel 2004), are important regulators of eukaryotic gene expression and the SNP at miRNAs target genes are associated with the human disease (Sethupathy and Collins 2008). As the miRNAs target genes, the EPASI and EGLN1 have significant SNPs between the Tibetan and Han populations; hence, studying the function of miRNAs could provide better understanding on Tibetans high-altitude adaptation. Furthermore, the protein-protein interactions (PPIs) could provide insight into protein function and facilitate the modeling of functional pathways to elucidate the molecular mechanisms of biological processes (Lin et al. 2006). Owing to the importance of the PPIs involved in the EPAS1, EGLN1 and HIF1A, as well as the miRNAs as the key posttranscriptional regulators of them, the PPIs and miRNAs network constructe]ion is required through the database mining to get better understanding of the role of the EPAS1 and EGLN1 in high-altitude adaptation process. What biological processes and biological pathways are involved in the PPIs network and miRNAs network, and whether the miRNAs contribute to the high altitude adaptation are still relatively unexplored. For this reason, this work further performed the systems biology study to explore the functional biological processes and pathways involved in the hypoxia adaptation, which could provide better insight to the high-altitude adaptation process. Furthermore, the systems biology approach could improve the understanding of the molecular basis of high-altitude adaptation and might identify the key functional pathways or relate molecular events of the disease caused by the high-altitude hypoxia.

\section{METHODS}

\section{PPIs and miRNAs network}

The PPI databases such as BioGRID (Stark et al. 2011) (http:// thebiogrid.org/) and Human Protein Reference Database (Keshava Prasad et al. 2009) (HPRD) (http://www. hprd.org/) were used to obtain the PPIs, including the EPAS1, EGLN1 and HIF1A. Although more than a hundred genes are regulated by the HIF1A, EPAS1 and EGLN1are the two key HIF regulatory genes encoding the 
transcription factors that induce the downstream genes when cellular oxygen levels decrease (Bigham et al. 2010; Ke and Costa 2006). Previous studies have shown that the incompleteness of the gene or proteins annotation repositories does not necessarily impair the computational function prediction (Jegga et al. 2011). In order to focus on the biological function enrichment analysis of the high-altitude adaptation of Tibetans, the database were mined and first-level PPIs of EPAS1, EGLN1 and HIF1A were constructed, which played key role in high-altitude adaptation of the Tibetans. The PPIs network included the indirect second-level PPIs.

MiRNAs, the regulators of the EPASI, EGLN1 and HIFIA, were obtained from the MicroCosm Targets (Griffiths-Jones et al. 2008). The PPIs and miRNAs were integrated to one network by the Cytoscape version 2.8.1, an open source software platform based on JAVA for visualizing and analyzing the genetic and molecular interaction complex networks and integrating these such as protein-protein, miRNA-gene, and genetic interactions (Cline et al. 2007). The PPIs and miRNAs were loaded into Cytoscape with different size and color node for visualizing as networks.

\section{Functional enrichment analysis of genes in PPIs network}

In order to assess the relative functional enrichment of the genes corresponding to the proteins in the PPIs, the Gene Ontology (GO) Consortium, Genecodis vision 2.0 (Carmona-Saez et al. 2007; Nogales-Cadenas et al. 2009) online tool, a web server application for functional analysis of in the large lists of genes or proteins that integrated different sources of information and found the modular patterns of interrelated annotations, was used for functional cluster analysis, including the biological processes, molecular function and biological pathways. The biological processes annotations were obtained from the Gene Ontology (http://www. geneontology. org/) and pathway annotations were obtained from the KEGG (Kanehisa et al. 2010; Kanehisa et al. 2006). All the data base es selected the Homo sapiens as reference.

\section{Functional enrichment analysis of miRNAs in network}

In order to assess the relative functional enrichment of miRNAs corresponding to the genes in the network, the miTALOS (http://mips.helmholtz-muenchen.de/mitalos/ index.jsp) online tool (Kowarsch et al. 2011), a web server application for providing the insight into miRNA-mediated regulation of signaling pathways, was used for the biological pathways cluster analysis. The Target, ScanTarget, SpyRNA22 and PicTar programs, which were compiled in miTALOS, were used together for the target gene prediction in order to get more biological pathways. The biological pathways annotations were obtained from the KEGG (Kanehisa et al. 2010; Kanehisa et al. 2006), which were compiled and stored in the miTALOS. The organism was human; the enrichment was 1.00 , and P-Value (E) was 0.05 .

\section{RESULTS AND DISCUSSION}

A network containing 92 proteins and 46 miRNAs (nodes) and 157 interactions (edges) was constructed (Fig 1).

\section{Genes functional enrichment analysis}

To find the functional biological processes and pathways, which contributed to the high-altitude adaptation, each gene in the network was categorized based on the biological processes (Table 1), cellular component (Table 2), molecular function (Table 3 ), and pathways (Table 4).

The biological processes enrichment results revealed that the genes in the PPIs involved in response to the hypoxia, positive and negative regulation of transcription from the RNA polymerase II promoter, regulation of transcription, chromatin remodeling and negative regulation of apoptosis, in addition, nerve growth factor receptor signaling pathway and negative regulation of myotube differentiation were included (Table 1). The molecular function enrichment analysis showed that the genes located in the nucleus, nucleoplasm and cytoplasm (Table 2) participated in the transcription factor binding, protein binding, DNA binding, NAD-dependent histone deacetylase activity and ubiquitin binding (Table 3). The pathways annotation results revealed the ErbB signaling pathway, Wnt signaling pathway, MAPK signaling pathway and cancer pathway (Table 4). 


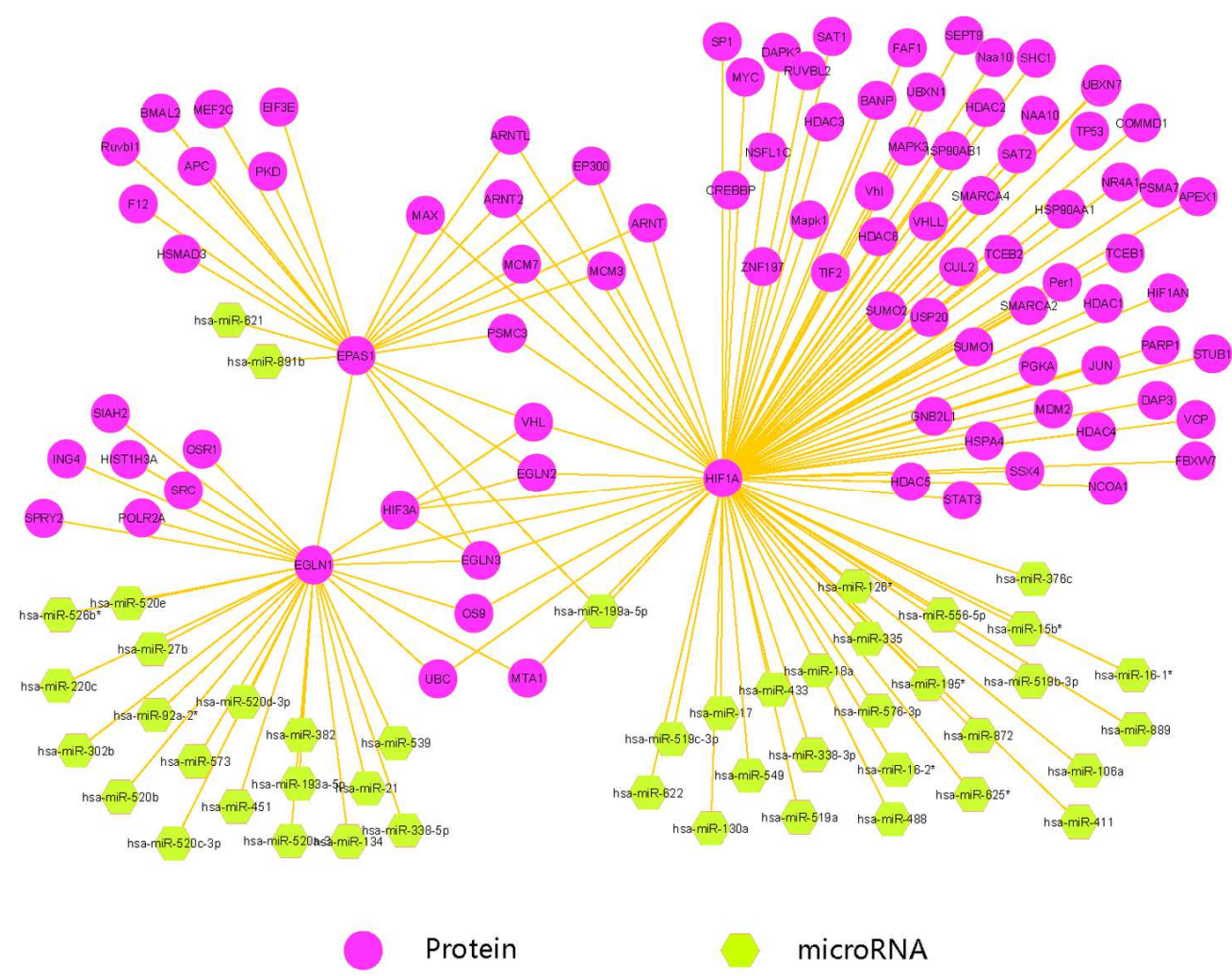

Figure 1 - An overview of PPIs and microRNAs network including EPAS1, EGLN1 and HIF1A; Network representation of the proteins that have interaction with EPAS1, EGLN1 and HIF1A and microRNA regulators that may be important in high-altitude adaptation of Tibetans.

Table 1 - Biological processes enrichment of genes in PPIs network.

\begin{tabular}{|c|c|c|c|c|}
\hline Biological process & Hyp & Нyр* & NGR & NG \\
\hline positive regulation of transcription from RNA polymerase II promoter & $5.03 \mathrm{E}-19$ & $3.76 \mathrm{E}-16$ & 525 & 21 \\
\hline interspecies interaction between organisms & $5.07 \mathrm{E}-16$ & $1.89 \mathrm{E}-13$ & 326 & 16 \\
\hline regulation of transcription, DNA-dependent & 7.31E-16 & $1.82 \mathrm{E}-13$ & 1610 & 28 \\
\hline positive regulation of transcription, DNA-dependent & $5.70 \mathrm{E}-15$ & $1.07 \mathrm{E}-12$ & 458 & 17 \\
\hline response to hypoxia & $4.88 \mathrm{E}-14$ & 7.30E-12 & 173 & 12 \\
\hline nerve growth factor receptor signaling pathway & $6.54 \mathrm{E}-13$ & $8.15 \mathrm{E}-11$ & 215 & 12 \\
\hline negative regulation of transcription from RNA polymerase II promoter & $1.47 \mathrm{E}-12$ & $1.57 \mathrm{E}-10$ & 372 & 14 \\
\hline histone deacetylation & 8.67E-12 & $8.10 \mathrm{E}-10$ & 19 & 6 \\
\hline chromatin modification & $2.30 \mathrm{E}-11$ & $1.91 \mathrm{E}-09$ & 222 & 11 \\
\hline negative regulation of transcription, DNA-dependent & $5.73 \mathrm{E}-11$ & 4.29E-09 & 398 & 13 \\
\hline $\begin{array}{l}\text { positive regulation of proteasomal ubiquitin-dependent protein catabolic } \\
\text { process }\end{array}$ & $1.48 \mathrm{E}-10$ & $1.01 \mathrm{E}-08$ & 29 & 6 \\
\hline negative regulation of myotube differentiation & $2.50 \mathrm{E}-10$ & $1.56 \mathrm{E}-08$ & 5 & 4 \\
\hline positive regulation of receptor biosynthetic process & 1.74E-09 & $1.00 \mathrm{E}-07$ & 7 & 4 \\
\hline transcription, DNA-dependent & 3.41E-09 & 1.82E-07 & 557 & 13 \\
\hline chromatin remodeling & $6.06 \mathrm{E}-09$ & 3.02E-07 & 52 & 6 \\
\hline positive regulation by host of viral transcription & $6.24 \mathrm{E}-09$ & $2.92 \mathrm{E}-07$ & 9 & 4 \\
\hline negative regulation of apoptosis & $1.41 \mathrm{E}-08$ & $6.22 \mathrm{E}-07$ & 232 & 9 \\
\hline
\end{tabular}

Hyp = Hypergeometric pValue; Hyp* = Corrected hypergeometric pValue; NG = Number of annotated genes in the input list; $\mathrm{NGR}=$ Number of annotated genes in the reference list; they are the same meaning in Table 2-4. 


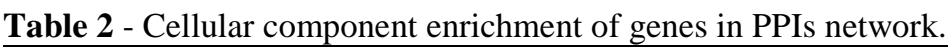

\begin{tabular}{|c|c|c|c|c|}
\hline Cellular component & Нyр & Нур* & NGR & NG \\
\hline nucleus & $7.95 \mathrm{E}-37$ & $9.86 \mathrm{E}-35$ & 5239 & 67 \\
\hline nucleoplasm & $3.77 \mathrm{E}-25$ & $2.34 \mathrm{E}-23$ & 889 & 30 \\
\hline cytoplasm & $6.96 \mathrm{E}-24$ & $2.88 \mathrm{E}-22$ & 5081 & 55 \\
\hline nucleolus & $1.26 \mathrm{E}-14$ & $3.89 \mathrm{E}-13$ & 1107 & 23 \\
\hline cytosol & $9.26 \mathrm{E}-13$ & $2.3 \mathrm{E}-11$ & 2148 & 28 \\
\hline Cdc48p-Npl4p-Ufd1p AAA ATPase complex & $5.00 \mathrm{E}-11$ & $1.03 \mathrm{E}-09$ & 4 & 4 \\
\hline transcription factor complex & $5.71 \mathrm{E}-09$ & $1.01 \mathrm{E}-07$ & 209 & 9 \\
\hline nuclear chromatin & $1.32 \mathrm{E}-08$ & $2.05 \mathrm{E}-07$ & 59 & 6 \\
\hline histone deacetylase complex & $1.46 \mathrm{E}-08$ & $2.01 \mathrm{E}-07$ & 29 & 5 \\
\hline
\end{tabular}

Table 3 - Molecular function enrichment of genes in PPIs network.

\begin{tabular}{|c|c|c|c|c|}
\hline Molecular function & Hyp & Нyр* & NGR & NG \\
\hline protein binding & $3.66 \mathrm{E}-41$ & $7.43 \mathrm{E}-39$ & 4271 & 66 \\
\hline transcription factor binding & $7.17 \mathrm{E}-24$ & $7.28 \mathrm{E}-22$ & 257 & 20 \\
\hline DNA binding & $8.74 \mathrm{E}-14$ & $5.91 \mathrm{E}-12$ & 1791 & 27 \\
\hline NAD-dependent histone deacetylase activity (H3-K14 specific) & $1.50 \mathrm{E}-13$ & $5.08 \mathrm{E}-12$ & 11 & 6 \\
\hline histone deacetylase activity (H3-K16 specific) & $1.50 \mathrm{E}-13$ & $5.08 \mathrm{E}-12$ & 11 & 6 \\
\hline NAD-dependent histone deacetylase activity (H4-K16 specific) & $1.50 \mathrm{E}-13$ & $5.08 \mathrm{E}-12$ & 11 & 6 \\
\hline sequence-specific DNA binding transcription factor activity & $5.45 \mathrm{E}-13$ & $1.58 \mathrm{E}-11$ & 936 & 20 \\
\hline NAD-dependent histone deacetylase activity (H3-K9 specific) & $5.55 \mathrm{E}-13$ & $1.25 \mathrm{E}-11$ & 13 & 6 \\
\hline histone deacetylase activity & $5.55 \mathrm{E}-13$ & $1.25 \mathrm{E}-11$ & 13 & 6 \\
\hline transcription coactivator activity & $1.89 \mathrm{E}-11$ & $3.84 \mathrm{E}-10$ & 218 & 11 \\
\hline histone deacetylase binding & $1.00 \mathrm{E}-10$ & $1.85 \mathrm{E}-09$ & 52 & 7 \\
\hline transcription regulatory region DNA binding & $5.74 \mathrm{E}-10$ & $9.72 \mathrm{E}-09$ & 161 & 9 \\
\hline ubiquitin protein ligase binding & $7.76 \mathrm{E}-10$ & $1.21 \mathrm{E}-08$ & 112 & 8 \\
\hline protein deacetylase activity & $3.47 \mathrm{E}-09$ & $5.04 \mathrm{E}-08$ & 8 & 4 \\
\hline aryl hydrocarbon receptor binding & $1.92 \mathrm{E}-08$ & $2.59 \mathrm{E}-07$ & 3 & 3 \\
\hline ubiquitin binding & $2.45 \mathrm{E}-08$ & $3.11 \mathrm{E}-07$ & 32 & 5 \\
\hline histone acetyltransferase binding & $3.51 \mathrm{E}-08$ & 4.19E-07 & 13 & 4 \\
\hline sequence-specific DNA binding & 3.98E-08 & $4.48 \mathrm{E}-07$ & 564 & 12 \\
\hline Hsp90 protein binding & 4.91E-08 & $5.24 \mathrm{E}-07$ & 14 & 4 \\
\hline TPR domain binding & $7.65 \mathrm{E}-08$ & $7.77 \mathrm{E}-07$ & 4 & 3 \\
\hline
\end{tabular}

Table 4 - Biological pathways enrichment of genes in PPIs network

\begin{tabular}{|c|c|c|c|c|}
\hline KEGG pathway & Hyp & Нyр* & NGR & NG \\
\hline Pathways in cancer & $4.91 \mathrm{E}-33$ & $3.97 \mathrm{E}-31$ & 325 & 27 \\
\hline Renal cell carcinoma & $3.99 \mathrm{E}-27$ & $1.62 \mathrm{E}-25$ & 70 & 16 \\
\hline Chronic myeloid leukemia & $2.39 \mathrm{E}-11$ & $6.45 \mathrm{E}-10$ & 73 & 8 \\
\hline Cell cycle & $5.54 \mathrm{E}-11$ & $1.12 \mathrm{E}-09$ & 124 & 9 \\
\hline Prostate cancer & $1.11 \mathrm{E}-10$ & $1.79 \mathrm{E}-09$ & 88 & 8 \\
\hline Bladder cancer & $1.59 \mathrm{E}-09$ & $2.15 \mathrm{E}-08$ & 42 & 6 \\
\hline Colorectal cancer & $1.79 \mathrm{E}-08$ & 2.07E-07 & 62 & 6 \\
\hline Ubiquitin mediated proteolysis & $8.65 \mathrm{E}-08$ & $8.76 \mathrm{E}-07$ & 135 & 7 \\
\hline TGF-beta signaling pathway & $1.05 \mathrm{E}-07$ & $9.45 \mathrm{E}-07$ & 83 & 6 \\
\hline
\end{tabular}

\section{MiRNAs functional enrichment analysis}

To further investigate the relationship between the miRNAs and molecular pathways, which were in the major human organs, including cerebellum, heart, liver, kidney, lung and smoothmuscle, the miRNAs involved in the biological pathways, enrichment analysis was explored by the miTALOS online tool. The pathways annotation analyses showed that the miRNAs were involved in the MAPK signaling pathway, $\mathrm{T}$ cell receptor signaling pathway and insulin signaling pathway (Table 5). 
Table 5 - Pathways enrichment of microRNAs in network.

\begin{tabular}{|c|c|c|c|c|c|c|c|c|c|c|c|c|}
\hline \multirow[t]{2}{*}{ Biological pathway } & \multicolumn{2}{|c|}{ cerebellum } & \multicolumn{2}{|c|}{ heart } & \multicolumn{2}{|c|}{ liver } & \multicolumn{2}{|c|}{ kidney } & \multicolumn{2}{|c|}{ lung } & \multicolumn{2}{|c|}{$\begin{array}{c}\text { Smooth } \\
\text { muscle }\end{array}$} \\
\hline & $E$ & $\mathrm{P}$ & $E$ & $\mathrm{P}$ & E & $\mathrm{P}$ & $E$ & $\mathrm{P}$ & $\mathrm{E}$ & $\mathrm{P}$ & $\mathrm{E}$ & $\mathrm{P}$ \\
\hline Insulin signaling pathway & 2.32 & 0.47 & -- & -- & -- & -- & -- & -- & -- & -- & -- & -- \\
\hline $\begin{array}{l}\mathrm{T} \text { cell receptor signaling } \\
\text { pathway }\end{array}$ & 2.47 & 0.38 & -- & -- & -- & -- & -- & -- & 2.64 & 0.38 & -- & -- \\
\hline MAPK signaling pathway & 1.76 & 0.43 & -- & -- & 1.95 & 0.4 & -- & -- & 2.19 & 0.43 & 1.65 & 0.4 \\
\hline Tight junction & -- & -- & -- & -- & -- & -- & -- & -- & 2.49 & 0.38 & -- & -- \\
\hline Long-term potentiation & -- & -- & 2.47 & 0.25 & 2.71 & 0.25 & -- & -- & -- & -- & -- & -- \\
\hline Acute myeloid leukemia & -- & -- & -- & -- & -- & -- & 2.93 & 0.27 & 3.06 & 0.27 & 2.58 & 0.27 \\
\hline Thyroid cancer & 4.06 & 1 & 3.36 & 1 & 3.85 & 1 & 3.54 & 1 & 4.39 & 1 & 3.45 & 1 \\
\hline
\end{tabular}

E=Enrichment; $p=$ Proximity; "--": irrelevance between microRNAs and pathways

These results together reflected the complicated biological processes and pathways of the EPAS1 and EGLN1 involved, which were intimately associated with the high-altitude adaptation of the Tibetan populations. The system biology approach provided further understanding of the function of miRNAs that were regulators of the EPASI, EGLN and HIF1A. Interestingly, the miRNAs functional cluster results showed that such function as MAPK signaling pathway was consistent with the genes biological pathway cluster analysis results. The pathways enrichment of the miRNAs analysis indicated that the miRNAs might contribute to the Tibetans high-altitude adaptation through participating in signaling pathway.

The EGLN1 is involved in cellular oxygen sensing and certain EGLN1 mutations lead to polycythemia (Percy et al. 2006). The higher expression of EGLN1 is inversely correlated to HIF activity (Aggarwal et al. 2010). The EGLN1 is associated with lower hemoglobin levels in the Tibetans (Simonson et al. 2010). There is strong and significant association between the hemoglobin concentration and haplotype variation at the EGLN1 (Percy et al. 2006; Simonson et al. 2010). Yet, high hemoglobin acclimatization can cause stokes, heart attacks and pulmonary embolisms.

The present results showed that most proteins in the PPIs network were involved in the hypoxia response mainly participate in signaling pathways. The EPAS1 and EGLN1 were the key genes that provided the Tibetans the hypoxia adaption ability. The hypoxia-response pathways in the humans are very complex. The biological processes, molecular function and pathways involved in the EGLN1 and
EPAS1 help to understand the high-altitude adaptation of Tibetans.

Tibetans have the hypoxia adaptation ability and hypoxic preconditioning can reduce the severity of induced or inherited degeneration in the tissues such as the brain (Emerson et al. 1999), heart (Cai et al. 2003) and the retina (Grimm et al. 2002; Thiersch et al. 2008). The EPAS1 is a transcription factor regulating the gene expression in response to the hypoxia (Tian et al. 1997), and the expression of EPAS1 is cell type-restricted. It is predominantly expressed in the vascular endothelial cells, lung epithelial cells and cardiac myocytes. In addition to the hypoxic response function, the EGLN1 is being considered as an important pharmacological target (Aggarwal et al. 2010). Thus, it could be hypothesized that whether the genes, such as EPAS1 and EGLN1 with significant difference SNPs that provide the Tibetans high-altitude adaptation ability, could make them avoid some kind of disease related with the hypoxia would be very interesting.

In conclusion, the system biology analysis of the EPAS1 and EGLN1, which have significant difference SNPs between the Tibetan and Han populations contribute to provide better understanding on the Tibetans high-altitude adaptation.

\section{ACKNOWLEDGEMENT}

This work was supported by the grants from the National Natural Science Foundation of China (11072023 to X. D.). 


\section{REFERENCES}

Aggarwal S, Negi S, Jha P, Singh PK, Stobdan T, Pasha MA, et al. EGLN1 involvement in high-altitude adaptation revealed through genetic analysis of extreme constitution types defined in Ayurveda. Proc Natl Acad Sci U S A. 2010; 107(44): 18961-18966.

Bartel DP. MicroRNAs: genomics, biogenesis, mechanism, and function. Cell. 2004; 116(2): 281297.

Basnyat B, Murdoch DR. High-altitude illness. Lancet. 2003; 361(9373): 1967-1974.

Beall CM. Two routes to functional adaptation: Tibetan and Andean high-altitude natives. Proc Natl Acad Sci U S A. 2007; 104 Suppl 1: 8655-8660.

Beall CM, Cavalleri GL, Deng L, Elston RC, Gao Y, Knight $J$, et al. Natural selection on EPAS1 (HIF2alpha) associated with low hemoglobin concentration in Tibetan highlanders. Proc Natl Acad Sci U S A. 2010; 107(25): 11459-11464.

Bigham A, Bauchet M, Pinto D, Mao X, Akey JM, Mei $\mathrm{R}$, et al. Identifying signatures of natural selection in Tibetan and Andean populations using dense genome scan data. PLoS Genet. 2010; 6(9)

Cai Z, Manalo DJ, Wei G, Rodriguez ER, Fox-Talbot $\mathrm{K}$, $\mathrm{Lu} \mathrm{H}$, et al. Hearts from rodents exposed to intermittent hypoxia or erythropoietin are protected against ischemia-reperfusion injury. Circulation. 2003; 108(1): 79-85.

Carmona-Saez P, Chagoyen M, Tirado F, Carazo JM, Pascual-Montano A. GENECODIS: a web-based tool for finding significant concurrent annotations in gene lists. Genome Biol. 2007; 8(1): R3.

Cline MS, Smoot M, Cerami E, Kuchinsky A, Landys $\mathrm{N}$, Workman $\mathrm{C}$, et al. Integration of biological networks and gene expression data using Cytoscape. Nat Protoc. 2007; 2(10): 2366-2382.

Emerson MR, Nelson SR, Samson FE, Pazdernik TL. A global hypoxia preconditioning model: neuroprotection against seizure-induced specific gravity changes (edema) and brain damage in rats. Brain Res Brain Res Protoc. 1999; 4(3): 360-366.

Griffiths-Jones S, Saini HK, van Dongen S, Enright AJ. miRBase: tools for microRNA genomics. Nucleic Acids Res. 2008; 36(Database issue): D154-158.

Grimm C, Wenzel A, Groszer M, Mayser H, Seeliger M, Samardzija M, et al. HIF-1-induced erythropoietin in the hypoxic retina protects against light-induced retinal degeneration. Nat Med. 2002; 8(7): 718-724.

Grosfeld A, Andre J, Hauguel-De Mouzon S, Berra E, Pouyssegur J, Guerre-Millo M. Hypoxia-inducible factor 1 transactivates the human leptin gene promoter. J Biol Chem. 2002; 277(45): 42953-42957.

Hu CJ, Wang LY, Chodosh LA, Keith B, Simon MC. Differential roles of hypoxia-inducible factor 1alpha (HIF-1alpha) and HIF-2alpha in hypoxic gene regulation. Mol Cell Biol. 2003; 23(24): 9361-9374.
Jegga AG, Schneider L, Ouyang X, Zhang J. Systems biology of the autophagy-lysosomal pathway. Autophagy. 2011; 7(5): 477-489.

Kanehisa M, Goto S, Furumichi M, Tanabe M, Hirakawa M. KEGG for representation and analysis of molecular networks involving diseases and drugs. Nucleic Acids Res. 2010; 38(Database issue): D355360.

Kanehisa M, Goto S, Hattori M, Aoki-Kinoshita KF, Itoh M, Kawashima $\mathrm{S}$, et al. From genomics to chemical genomics: new developments in KEGG. Nucleic Acids Res. 2006; 34(Database issue): D354357.

Ke Q, Costa M. Hypoxia-inducible factor-1 (HIF-1). Mol Pharmacol. 2006; 70(5): 1469-1480.

Keshava Prasad TS, Goel R, Kandasamy K, Keerthikumar S, Kumar S, Mathivanan S, et al. Human Protein Reference Database--2009 update. Nucleic Acids Res. 2009; 37(Database issue): D767772.

Kowarsch A, Preusse M, Marr C, Theis FJ. miTALOS: analyzing the tissue-specific regulation of signaling pathways by human and mouse microRNAs. RNA. 2011; 17(5): 809-819.

Lin C, Cho Y-r, Hwang WC, Pei P, Zhang A. Clustering Methods in a Protein-Protein Interaction Network. Knowledge Discovery in Bioinformatics: Techniques, Methods, and Applications : John Wiley \& Sons, Inc. 2006: Chapter 1:1-2.

Meixue Y, Frederick EN, Nikolay IS, Donglin G, Guoning W. Permafrost degradation and its environmental effects on the Tibetan Plateau: A review of recent research. . Earth-Science Reviews. 2010; 103: 31-44.

Nogales-Cadenas R, Carmona-Saez P, Vazquez M, Vicente C, Yang X, Tirado F, et al. GeneCodis: interpreting gene lists through enrichment analysis and integration of diverse biological information. Nucleic Acids Res. 2009; 37(Web Server issue): W317-322.

Patel SA, Simon MC. Biology of hypoxia-inducible factor-2alpha in development and disease. Cell Death Differ. 2008; 15(4): 628-634.

Peng Y, Yang Z, Zhang H, Cui C, Qi X, Luo X, et al. Genetic variations in Tibetan populations and highaltitude adaptation at the Himalayas. Mol Biol Evol. 2011; 28(2): 1075-1081.

Percy MJ, Zhao Q, Flores A, Harrison C, Lappin TR, Maxwell PH, et al. A family with erythrocytosis establishes a role for prolyl hydroxylase domain protein 2 in oxygen homeostasis. Proc Natl Acad Sci U S A. 2006; 103(3): 654-659.

Sethupathy P, Collins FS. MicroRNA target site polymorphisms and human disease. Trends Genet. 2008; 24(10): 489-497. 
Simonson TS, Yang Y, Huff CD, Yun H, Qin G, Witherspoon DJ, et al. Genetic evidence for highaltitude adaptation in Tibet. Science. 2010; 329(5987): 72-75.

Stark C, Breitkreutz BJ, Chatr-Aryamontri A, Boucher L, Oughtred R, Livstone MS, et al. The BioGRID Interaction Database: 2011 update. Nucleic Acids Res. 2011; 39(Database issue): D698-704.

Thiersch M, Raffelsberger W, Frigg R, Samardzija M, Wenzel A, Poch O, et al. Analysis of the retinal gene expression profile after hypoxic preconditioning identifies candidate genes for neuroprotection. $B M C$ Genomics. 2008; 9: 73.

Tian H, McKnight SL, Russell DW. Endothelial PAS domain protein 1 (EPAS1), a transcription factor selectively expressed in endothelial cells. Genes Dev. 1997; 11(1): 72-82.
Wang GL, Jiang BH, Rue EA, Semenza GL. Hypoxiainducible factor 1 is a basic-helix-loop-helix-PAS heterodimer regulated by cellular $\mathrm{O} 2$ tension. Proc Natl Acad Sci U S A. 1995; 92(12): 5510-5514.

$\mathrm{Wu}$ T, Kayser B. High altitude adaptation in Tibetans. High Alt Med Biol. 2006; 7(3): 193-208.

Xu S, Li S, Yang Y, Tan J, Lou H, Jin W, et al. A genome-wide search for signals of high-altitude adaptation in Tibetans. Mol Biol Evol. 2011; 28(2): 1003-1011.

Yi X, Liang Y, Huerta-Sanchez E, Jin X, Cuo ZX, Pool $\mathrm{JE}$, et al. Sequencing of 50 human exomes reveals adaptation to high altitude. Science. 2010; 329(5987): 75-78.
Received: August 01, 2011;

Revised: March 06, 2012; Accepted: September 21, 2012. 